\title{
Evaluation of Seismic Performance of Double-layer Steel Diagrid Systems
}

\author{
Ali Seyedkazemi ${ }^{1 *}$, Reza Qolian Seraji ${ }^{1}$ \\ ${ }^{1}$ Department of Civil Engineering, Faculty of Engineering, Ayatollah Amoli Branch, Islamic Azad University, Amol, P.O.B. 678, Iran \\ * Corresponding author, e-mail: a.seyedkazemi@iauamol.ac.ir
}

Received: 24 March 2018, Accepted: 05 October 2019, Published online: 28 November 2019

\begin{abstract}
A new type of structural systems, called diagrid, has been introduced in recent years, in which the diagonal members are often located in the exterior frames while the interior frames, including vertical columns, resist only the gravity loads. A novel double-layer diagrid system is proposed in this study and the equations related to its lateral stiffness are extracted. The combination of angles of internal and external diagonals is also investigated to obtain the desired stiffness. Eventually, considering a 12-story structural model, the seismic performance of the proposed system is investigated and compared with conventional diagrid systems through changing the angle of diagonals in interior and exterior frames. Results show that double-layer diagrid systems are more suitable than conventional diagrid systems in providing stiffness and strength criteria. Moreover, a proper combination of internal and external angles improves the ductility, as well as increasing the amount of energy dissipated by the structure.
\end{abstract}

Keywords

diagrid structures, seismic performance, steel structures, double-layer systems

\section{Introduction}

Diagrids are one of the most commonly used lateral and gravity load-bearing systems in high-rise buildings. The system of a diagrid commonly consists of a grid of diagonal elements surrounding the structure that leads to appropriate shear strength. The triangular configuration provides structural stability for gravity and lateral loads, and the removal of external columns gives the building a unique architectural beauty [1]. The angle of diagonals plays an important role in the structural behavior. Many researches have been conducted to examine the effect that the angle of diagonals can have on the performance of the structure under lateral loads (wind and earthquake) [1-5] and offered the optimal angle considering stiffness criterion [2]. Moreover, studies have shown that in addition to the stiffness criterion, consideration of the strength is also necessary in designing this system [6]. Some studies also revealed that besides the weight of the structure, three factors of stiffness, strength and ductility are effective in determining the diagonal angle leading to the best performance [7].
In most of the recent studies, diagrids surround the structure and interior frames along with vertical columns only resist gravity load. In this study, a double-layer diagrid system is proposed. The equations for the lateral stiffness of the system, which combines the stiffness of outer and inner frames, are extracted and analyzed. In the following, a 12-story structural model with double-layer diagrid system is modeled in PERFORM 3D software [8] and by changing the angle of the diagonal members in the interior and exterior frames and combining them, the seismic performance of the proposed system is examined. In seismic performance assessment of this system, non-linear static and dynamic analyses are used and the parameters such as weight, stiffness, strength, ductility, story drift ratio and energy dissipation are the main criteria for performance evaluation. Some advantages of the proposed system include the removal of columns in the inner parts of the structure, the possibility of distributing stiffness and consequently the dimension reduction of the cross-sections in the outer frames. The outcome of the aforementioned advantages is the improvement of architectural performance of the structure. 


\section{Investigation of the lateral stiffness of the double- layer diagrid system}

Fig. 1(a) depicts the plan of a double-layer diagrid system. In Figs. 1(b) and 1(c), exterior and interior diagrid frames of this system are shown. The lateral stiffness of two intersecting diagonals is calculated by Eq. (1):

$$
K_{H}=\frac{F_{H}}{\Delta},
$$

where $F_{H}$ is the lateral force and $\Delta$ is the drift between the two ends of the diagonal member, as shown in Fig. 2. If it is assumed that the diagonal members bear only the axial load, then for the calculation of $F_{H}$, the horizontal component of the axial forces created in the diagonal members is added together (Eq. (2)).

$$
F_{H}=\frac{\left(A_{d 1}+A_{d 2}\right) E}{h} \Delta \sin \theta \cos ^{2} \theta
$$

where $A_{d 1}$ and $A_{d 2}$ stand for cross-section area of diagonal elements, $E$ is modulus of elasticity, $h$ is story height and $\theta$ is the angle of the diagonal member. Using Eqs. (1) and (2) we have:

$K_{H}=\frac{\left(A_{d 1}+A_{d 2}\right) E}{h} \sin \theta \cos ^{2} \theta$.

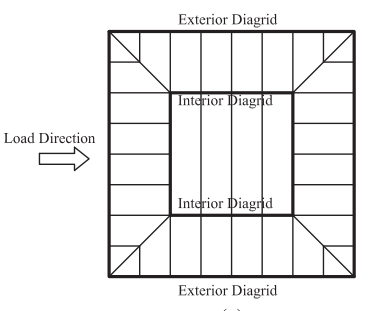

(a)

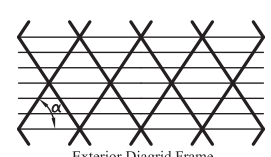

(b)

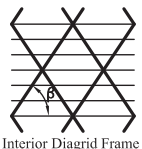

(c)
Fig. 1 A double-layer diagrid system: (a) Plan, (b) Exterior diagrid frame, (c) Interior diagrid frame

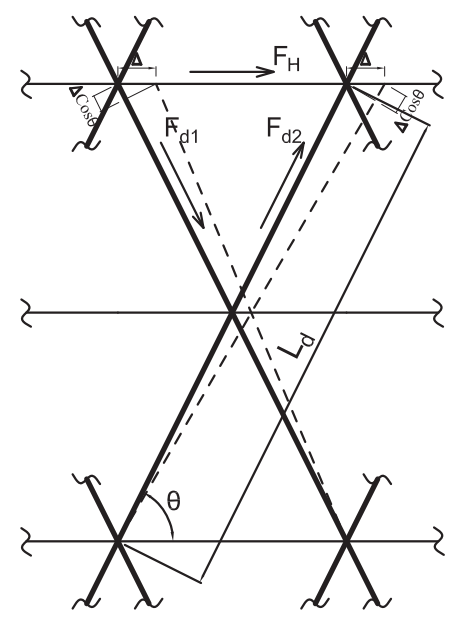

Fig. 2 Lateral displacement and the axial force of diagonal elements
If the diaphragm of floors are assumed to be rigid, the total lateral stiffness of the structure is obtained using Eq. (4):

$K=K_{e x}+K_{i n}=\frac{\left(\sum_{i=1}^{n_{1}} A_{e x, d i}\right) E}{h} \sin \alpha \cos ^{2} \alpha$

$+\frac{\left(\sum_{j=1}^{n_{2}} A_{i n, d j}\right) E}{h} \sin \beta \cos ^{2} \beta$,

where $K_{e x}$ and $K_{\text {in }}$ are the lateral stiffness of exterior and interior diagrid frames, respectively. $n_{1}, n_{2}, \sum A_{e x, d i}, \sum A_{i n, d i}$, $h, \alpha$ and $\beta$ are number of diagonal elements in exterior frame, number of diagonal elements in interior frame, total cross-section areas of the external diagonals, total cross-section areas of the internal diagonals, story height, angle between external diagonals with horizontal plane and the angle of internal diagonals with horizontal plane, respectively. If it is assumed $N=\sum_{i=1}^{n_{i}} A_{e x, d i} / \sum_{j=1}^{n_{2}} A_{i n, d j}$, then:

$K=\frac{E \sum_{j=1}^{n_{2}} A_{i n, d j}}{h}\left(N \sin \alpha \cos ^{2} \alpha+\sin \beta \cos ^{2} \beta\right)$.

In Fig. 3 the surfaces $N \sin \alpha \cos ^{2} \alpha+\sin \beta \cos ^{2} \beta$ for $N=2,3$ and 4 are presented.

According to the figure, the maximum lateral stiffness is obtained when the angles of members in both interior and exterior diagrids are $35^{\circ}$. Moreover, for a specific external angle, with increasing the angle of elements in interior diagrid, the stiffness of the system reduces (in case that the angle of elements are more than $35^{\circ}$ ). This system allows to designer vary the dimension of internal and external cross sections according to the intended architectural function. This can be achieved by variation of $\mathrm{N}$ and accordingly, stiffness concentration in interior or exterior frames. Furthermore, there are several alternatives for selecting internal and external angles in order to achieve the desired stiffness for a specific $N$ (i.e., without changing the cross sections of the diagonals), which can also further enhance the architectural efficiency of the system. For example, for $N=2.5$, two solutions of a) selecting the same internal and external angles as 65 degrees; and b) selecting the external angle of 73 degrees and internal angle of 43 degrees have a same result.

\section{Design of structural models and analysis modelling}

To investigate the seismic performance of double-layer diagrid system, a 12-story building is selected with a story height of 3.2 meters. As shown in Fig. 4, the plan of buildings 


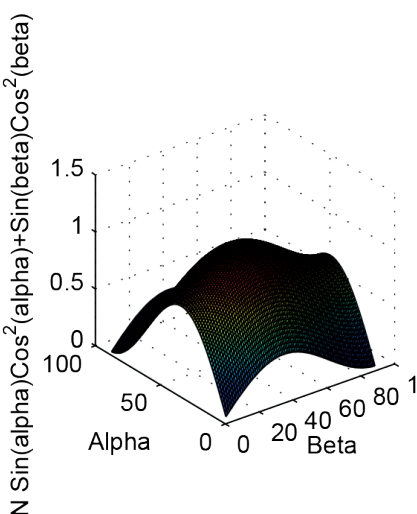

(a) $N=2$

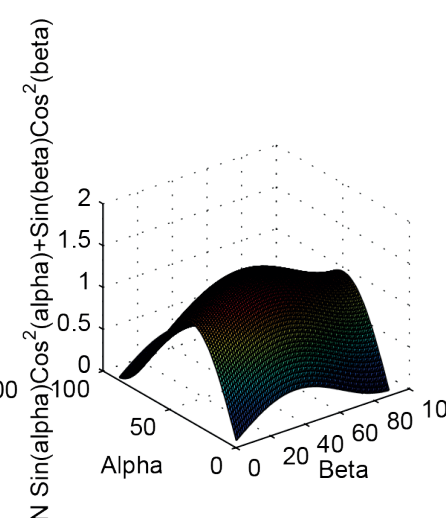

(b) $\mathrm{N}=3$

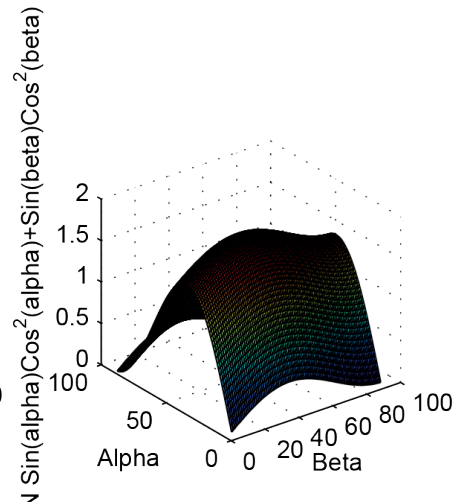

(c) $\mathrm{N}=4$

Fig. $3 N \sin \alpha \cos ^{2} \alpha+\sin \beta \cos ^{2} \beta$ : (a) $N=2$, (b) $N=3$, (c) $N=4$

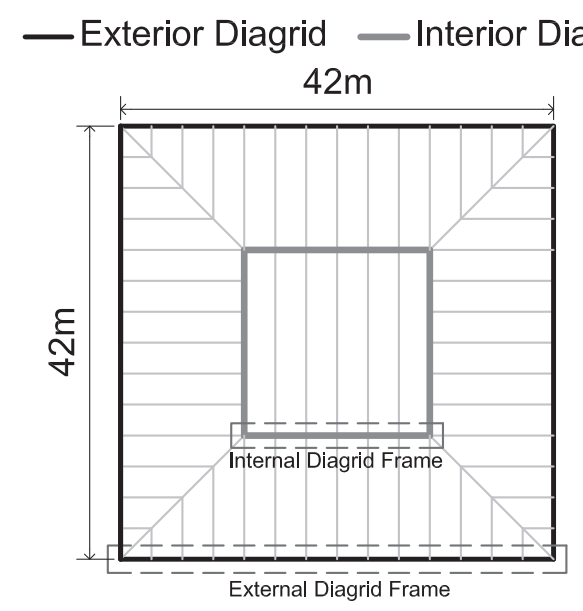

Fig. 4 Plan of the studied structures

is square with the side length of 42 meters consisting of two external and internal diagrid layers. The diagonal members were located at 6 meter spacing along the interior and exterior diagrid frames. In this study, five internal and external angles of 47, 65, 73, 77 and 90 degrees were used.
The combination of internal and external angles leads to 25 models that are studied. Except for $90^{\circ}$ (i.e., vertical columns), pinned connections are considered for the diagonal members in all the interior and exterior diagrid frames. When the angle of the columns is $90^{\circ}$ in the outer frame, they are spaced at 3 meters from each other and the beamto-column connections are assumed to be rigid. Interior frames with $90^{\circ}$ columns only bear gravity load and thus were pin-connected. Fig. 5 shows the interior and exterior diagrid frames. Seismic design forces and displacements are calculated based on the equivalent lateral force (ELF) and the response spectrum analysis (RSA) procedures of ASCE 7-10 [9]. The design spectral acceleration parameters are assumed to be $S_{D S}=1 \mathrm{~g}$ and $S_{D 1}=0.6 \mathrm{~g}$. Seismic design category is considered as $D$, risk category as $I I$, soil type as stiff soil (site class $D$ ) and damping ratio as $5 \%$. Dead and live loads are considered $6.4 \mathrm{kN} / \mathrm{m}^{2}$ and $2.45 \mathrm{kN} /$ $\mathrm{m}^{2}$ respectively. In all structures, $\mathrm{W}$ sections for beams and Box sections for diagonal members and columns are

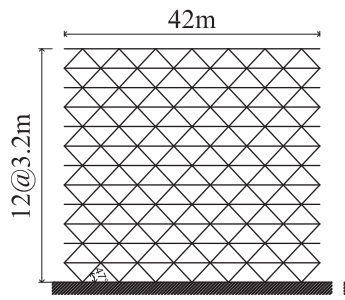

(a) $\alpha=47^{\circ}$

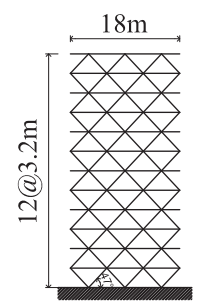

(f) $\beta=47^{\circ}$

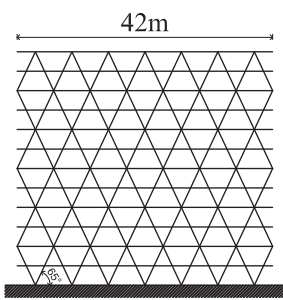

(b) $\alpha=65^{\circ}$

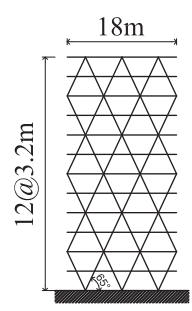

(g) $\beta=65^{\circ}$

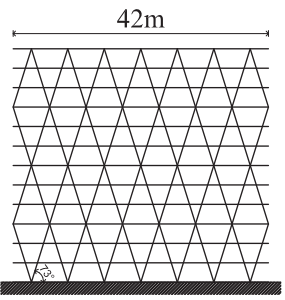

(c) $\alpha=73^{\circ}$

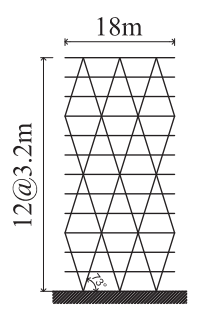

(h) $\beta=73^{\circ}$

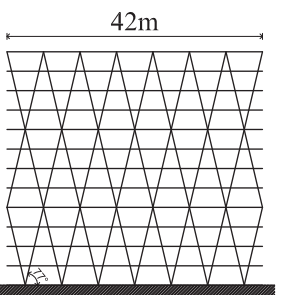

(d) $\alpha=77^{\circ}$

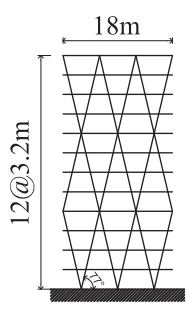

(i) $\beta=77^{\circ}$

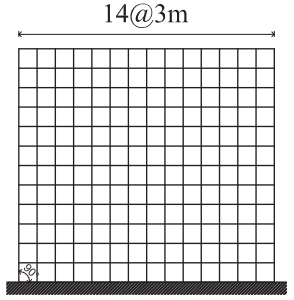

(e) $\alpha=90^{\circ}$

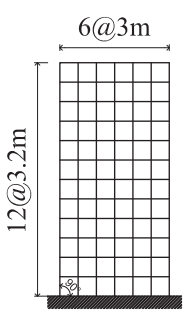

(j) $\beta=90^{\circ}$

Fig. 5 Exterior and interior frames in the studied structures: (a-e) Exterior frames, (f-j) Interior frames 
used. Structural design is carried out using LRFD method in accordance with AISC 360-10 [10]. The design of structural models is done using ETABS software [11] and PERFORM 3D software is employed for performing nonlinear static and dynamic analyses.

In Table 1, the design base shears $\left(V_{d}\right)$ and the modal properties of the structures are shown. The phrase $E \alpha I \beta$ is used to name the models where $\alpha$ and $\beta$ are the angles of the diagonal members in exterior and interior frames, respectively. In this table, the structural models with external moment-resisting frames (i.e., models with vertical columns in exterior frames) were separated. The results show that by the assumption of constant external angle, with increasing the internal angle, the fundamental period and the mass participation factor of the fundamental mode increase.

\section{Nonlinear static analysis and investigation of results}

The force-deformation relationships for elements with axial and flexural behavior are shown in Fig. 6, where $\theta$ is the angle of rotation, $\Delta$ is the displacement, $P_{y}$ is the yield strength, and $P_{c r}$ is the buckling strength. The parameters $a, b$ and $c$ which depend on the width-thickness ratio of the members, are obtained using the ASCE41-13 [12]. For nonlinear analyses, the PERFORM-3D software is used. The diagonal and vertical members are modeled using a "Column Inelastic Fiber Section" based on material properties defined as "Inelastic Steel Material, Buckling". Beam elements are modeled as nonlinear elements of "FEMA Beam, Steel Type". The lateral load pattern is considered to be in proportion to the fundamental mode shape of the structure according to the ASCE41-13.

Table 1 Design base shear and dynamic properties of structures

\begin{tabular}{|c|c|c|c|c|c|}
\hline \multirow{2}{*}{ Model ID Number } & \multirow{2}{*}{$\begin{array}{c}\text { Angle of external } \\
\text { diagonals }\end{array}$} & \multirow{2}{*}{$V_{d}(\mathrm{kN})$} & \multirow{2}{*}{$V_{d} / W$} & \multicolumn{2}{|c|}{ Fundamental mode } \\
\hline & & & & Period (sec) & Modal participation mass (\%) \\
\hline E47I47 & \multirow[t]{5}{*}{47} & 69199.5 & 0.346 & 0.419 & 68.9 \\
\hline E47I65 & & 47772.7 & 0.248 & 0.439 & 72.6 \\
\hline E47I73 & & 53653.2 & 0.276 & 0.457 & 73.2 \\
\hline E47I77 & & 51551.1 & 0.266 & 0.459 & 73.4 \\
\hline E47I90 & & 40811.2 & 0.22 & 0.471 & 73.9 \\
\hline E65I47 & \multirow[t]{5}{*}{65} & 54117.0 & 0.276 & 0.455 & 70.9 \\
\hline E65I65 & & 51691.9 & 0.265 & 0.512 & 76.1 \\
\hline E65I73 & & 49278.2 & 0.253 & 0.527 & 77.5 \\
\hline E65I77 & & 55578.0 & 0.282 & 0.542 & 77.8 \\
\hline E65I90 & & 44575.4 & 0.234 & 0.557 & 78.3 \\
\hline E73I47 & \multirow[t]{5}{*}{73} & 53959.0 & 0.273 & 0.488 & 70.5 \\
\hline E73I65 & & 48324.2 & 0.248 & 0.570 & 76.5 \\
\hline E73I73 & & 49093.3 & 0.25 & 0.608 & 78.3 \\
\hline E73I77 & & 50060.9 & 0.25 & 0.611 & 80.4 \\
\hline E73I90 & & 44584.6 & 0.229 & 0.648 & 80.6 \\
\hline E77I47 & \multirow[t]{5}{*}{77} & 48820.6 & 0.248 & 0.517 & 69.6 \\
\hline E77I65 & & 44400.5 & 0.227 & 0.594 & 77.1 \\
\hline E77I73 & & 43686.2 & 0.221 & 0.648 & 79.0 \\
\hline E77I77 & & 46304.2 & 0.23 & 0.662 & 80.4 \\
\hline E77I90 & & 40961.7 & 0.208 & 0.738 & 80.6 \\
\hline \multicolumn{6}{|c|}{ Structural models with the external moment-resisting frames } \\
\hline E90I47 & \multirow[t]{5}{*}{90} & 54093.5 & 0.277 & 0.612 & 65.3 \\
\hline E90I65 & & 40646.2 & 0.215 & 0.672 & 73.1 \\
\hline E90I73 & & 38769.5 & 0.205 & 0.754 & 75.7 \\
\hline E90I77 & & 35149.5 & 0.186 & 0.857 & 77.9 \\
\hline E90I90 & & 30833.0 & 0.168 & 1.159 & 78.5 \\
\hline
\end{tabular}




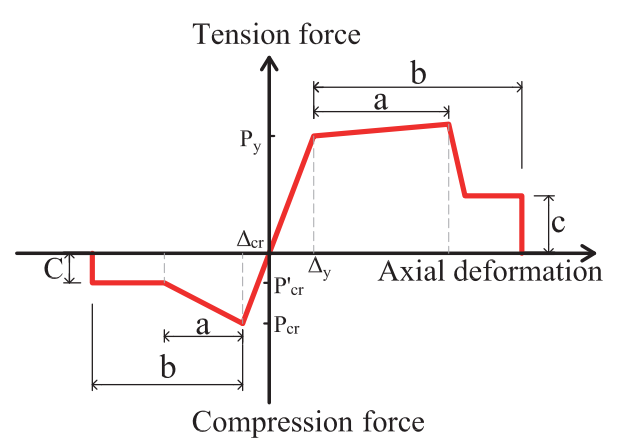

(a)

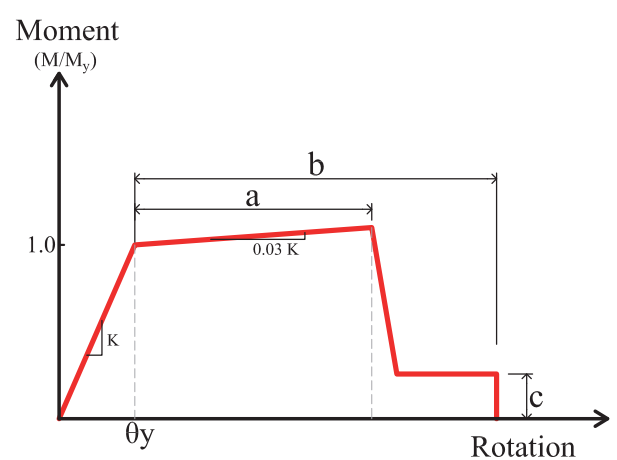

(b)

Fig. 6 Force-deformation relations of structural members: (a) members with axial behavior, (b) flexural members

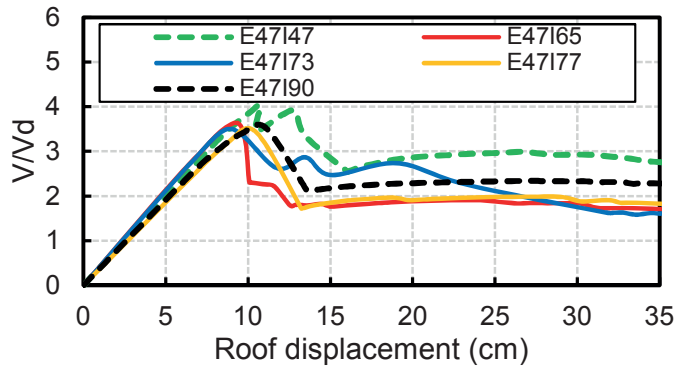

(a) The angle of $47^{\circ}$ for external diagonals

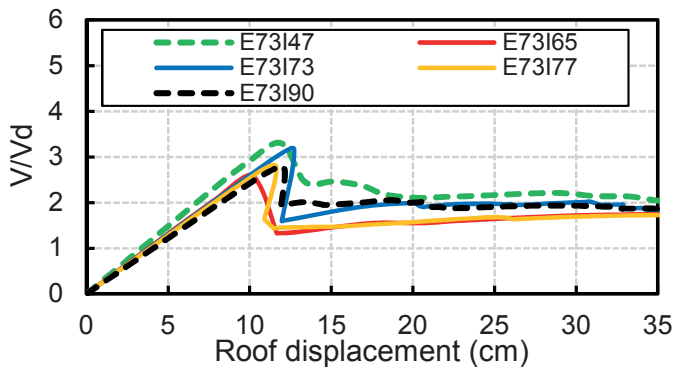

(c) The angle of $73^{\circ}$ for external diagonals

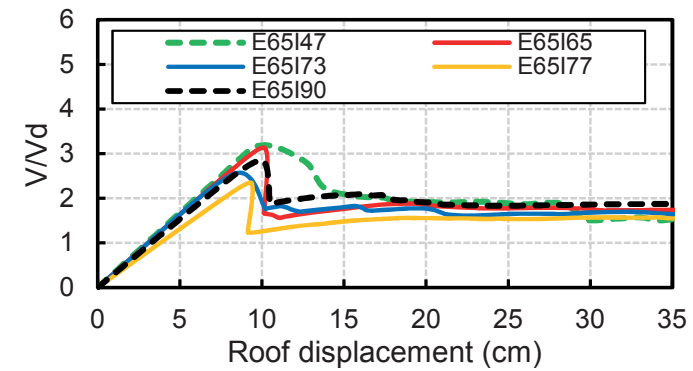

(b) The angle of $65^{\circ}$ for external diagonals

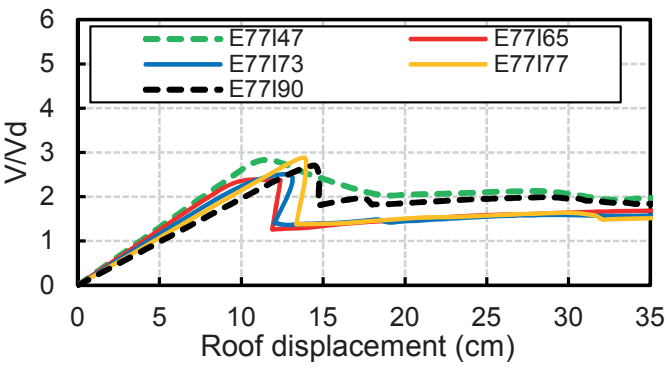

(d) The angle of $77^{\circ}$ for external diagonals

Fig. 7 Comparison of pushover curves for diagrid structures

Figs. 7(a)-7(d) depict the pushover curves (capacity curves) of diagrid structures with different angles for internal and external diagonal members. Since the objective is to compare the capacity curve of the double-layer diagrid structures with that of the conventional types (i.e. externally single-layer diagrid), therefore, in each of these figures, the angle of the members is kept constant in the exterior frame and the angles of the internal diagonals are changed. In these figures, the diagrams related to the diagrid structures in which the column angle of the interior frame is $90^{\circ}$ are shown as the dotted line and represent the conventional type of diagrid buildings (externally single-layer diagrid). For better comparison, the diagrams of the double-layer diagrid system with the angle of $47^{\circ}$ for internal diagonals are shown in the dotted lines too. Fig. 8 shows the pushover curves for the structures in which the interior frames are diagrid systems and the exterior frames are of the moment-resisting frame type with vertical columns. The information obtained from the pushover curves including yield strength $\left(V_{y}\right)$, maximum base shear $\left(V_{\max }\right)$, the yield roof displacement $\left(\delta_{y}\right)$, and ultimate or target displacement $\left(\delta_{u}\right)$ are summarized in Table 2. For calculating these quantities, the pushover curve of structures is replaced by an idealized bilinear curve as defined in ASCE 41-13. Based on the data obtained from the capacity curves, the parameters, stiffness $(K)$, strength $(R)$ and ductility $(\mu)$ are determined using Eqs. (6)-(8):

$$
\begin{aligned}
& R=V_{\text {max }}, \\
& K=V_{y} / \delta_{y}, \\
& \mu=\delta_{u} / \delta_{y} .
\end{aligned}
$$




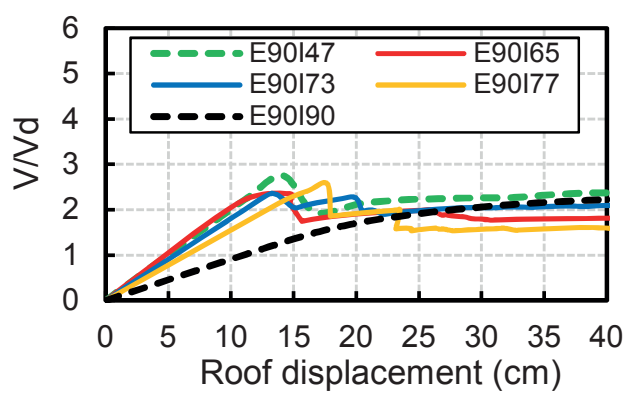

Fig. 8 Comparison of the pushover curves of the models with the external moment-resisting frame and internal diagrid system

Table 2 Summary of pushover results for the studied models

\begin{tabular}{lcccc}
\hline Model ID Number & $V_{v}(\mathrm{kN})$ & $V_{\max }(\mathrm{kN})$ & $\delta_{v}(\mathrm{~m})$ & $\delta_{u}(\mathrm{~m})$ \\
\hline E47I47 & 250155.0 & 278772.9 & 0.090 & 0.117 \\
E47I65 & 151662.6 & 173793.7 & 0.075 & 0.103 \\
E47I73 & 159804.9 & 188035.7 & 0.086 & 0.099 \\
E47I77 & 154998.0 & 177427.3 & 0.088 & 0.115 \\
E47I90 & 123606.0 & 144339.1 & 0.079 & 0.121 \\
E65I47 & 153526.5 & 172222.1 & 0.085 & 0.108 \\
E65I65 & 153820.8 & 161352.3 & 0.092 & 0.112 \\
E65I73 & 112815.0 & 125065.2 & 0.081 & 0.092 \\
E65I77 & 123213.6 & 129960.4 & 0.085 & 0.104 \\
E65I90 & 116248.5 & 126996.1 & 0.093 & 0.111 \\
E73I47 & 163925.1 & 178099.6 & 0.102 & 0.129 \\
E73I65 & 124194.6 & 125085.4 & 0.099 & 0.112 \\
E73I73 & 150289.2 & 156143.8 & 0.118 & 0.137 \\
E73I77 & 132336.9 & 141146.4 & 0.104 & 0.126 \\
E73I90 & 120859.2 & 124373 & 0.112 & 0.131 \\
E77I47 & 122625.0 & 138036.4 & 0.096 & 0.123 \\
E77I65 & 103397.4 & 105484.6 & 0.093 & 0.134 \\
E77I73 & 99375.3 & 108317.4 & 0.110 & 0.141 \\
E77I77 & 121251.6 & 132787.1 & 0.122 & 0.149 \\
E77I90 & 103887.9 & 110497.8 & 0.130 & 0.155 \\
E90I47 & 136359.0 & 148568.4 & 0.125 & 0.152 \\
E90I65 & 91311.5 & 95550.48 & 0.111 & 0.157 \\
E90I73 & 90232.4 & 91497.33 & 0.132 & 0.143 \\
E90I77 & 80167.3 & 90405.7 & 0.147 & 0.187 \\
E90I90 & 62372.0 & 70374.03 & 0.225 & 0.583 \\
\hline & & & & \\
& & & \\
& 1525 &
\end{tabular}

The values of these parameters are determined in Section 6 and used to evaluate the performance of structures. Fig. 9 presents the results obtained for the stiffness of the structures using Eq. (5) as well as the pushover analysis. In this figure, the lateral stiffness of the structures is normalized in terms of the maximum lateral stiffness which is related to the model E47I47. As could be seen, by increasing the angle of internal and external diagonals, differences between the results calculated from the introduced

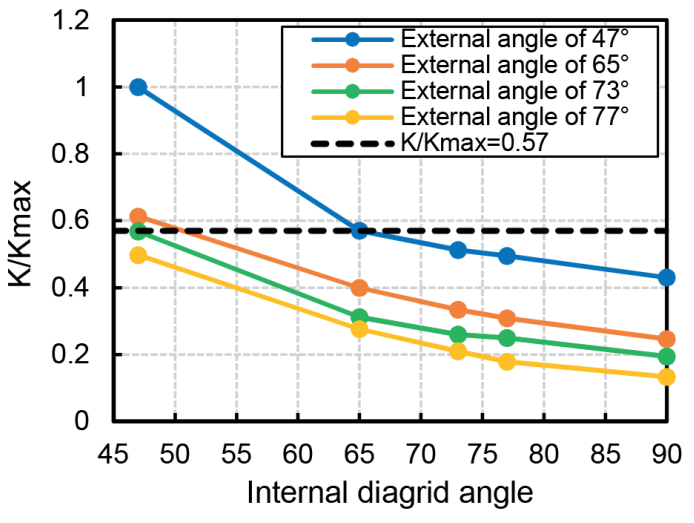

(a) From extracted equation

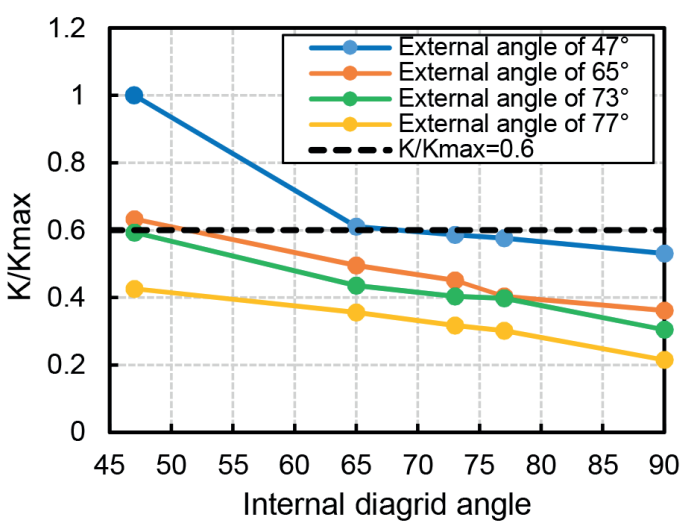

(b) From pushover analysis

Fig. 9 The results obtained for the stiffness of the structures

equation and the results from the accurate analysis via software, become more evident. This is due to an increase in the stiffness contribution rate of the frames perpendicular to the load direction, in the total lateral stiffness of the structure. For small diagonal angles, the results obtained from the introduced equation are consistent with the results obtained from the accurate analysis of the model via the software. As shown in Fig. 9, the values of $K$ in both of the cases: a) the external angle of $47^{\circ}$ and the internal angle of $65^{\circ}$; and b) the external angle of $73^{\circ}$ and the internal angle of $47^{\circ}$, are approximately equal. Therefore, the double layer diagrid structural system allows the designer to have various alternatives to provide the required stiffness of the structure. The comparison of pushover curves demonstrates the proper performance of double-layer diagrid systems in the energy dissipation (the area under the pushover curve) as well as satisfying the stiffness and strength requirements.

\section{Nonlinear dynamic analysis and survey results}

Seven pairs of far-field earthquake records are used in order to perform nonlinear dynamic time history analysis. Table 3 shows the characteristics of these ground motion records. 
Table 3 Characteristics of the far-field earthquake records

\begin{tabular}{|c|c|c|c|c|c|c|c|c|}
\hline \multirow{2}{*}{ EQ ID } & \multirow{2}{*}{ M } & \multirow{2}{*}{ Year } & \multirow{2}{*}{ Earthquake Name } & \multirow{2}{*}{ Recording Station } & \multicolumn{2}{|c|}{$P G A(\mathrm{~g})$} & \multicolumn{2}{|c|}{$P G V(\mathrm{~cm} / \mathrm{s})$} \\
\hline & & & & & Comp. 1 & Comp. 2 & Comp. 1 & Comp. 2 \\
\hline 1 & 6.7 & 1994 & Northridge & Beverly Hills - Mulhol & 0.443 & 0.488 & 59.295 & 66.717 \\
\hline 2 & 6.5 & 1979 & Imperial Valley & El Centro Array \#11 & 0.367 & 0.379 & 36.018 & 44.610 \\
\hline 3 & 6.9 & 1995 & Kobe, Japan & Nishi-Akashi & 0.483 & 0.464 & 46.825 & 38.263 \\
\hline 4 & 7.3 & 1992 & Landers & Coolwater & 0.284 & 0.417 & 27.615 & 43.419 \\
\hline 5 & 6.9 & 1989 & Loma Prieta & Capitola & 0.511 & 0.439 & 38.026 & 29.614 \\
\hline 6 & 6.5 & 1987 & Superstition Hills & Poe Road (temp) & 0.475 & 0.286 & 41.169 & 29.016 \\
\hline 7 & 7.6 & 1999 & Chi-Chi, Taiwan & TCU045 & 0.473 & 0.507 & 50.084 & 46.377 \\
\hline
\end{tabular}

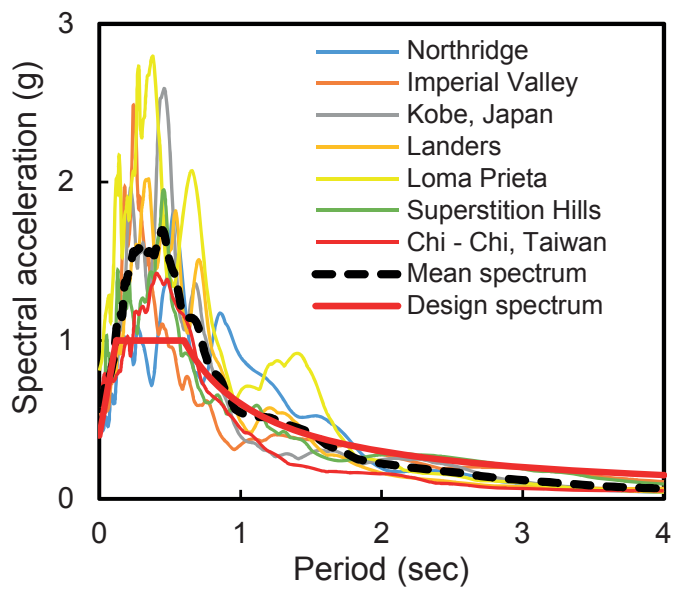

Fig. 10 Response spectra of selected earthquake records, mean spectra and design response spectrum

The response spectra of the ground motion records and their mean spectrum are depicted in Fig. 10 along with the design spectrum. The records are scaled according to ASCE7-10 and then used in nonlinear dynamic analysis. Figs. 11 and 12 show the maximum inter-story drift and the maximum roof displacement in the diagrid structures, respectively.

These figures represent the mean values obtained from the results of seven analyses in which the black dotted diagrams refer to the conventional diagrid model (single layer diagrid). It can be seen that in all double-layer diagrid structures, by increasing the angle of the diagonal members in exterior and interior diagrid frames, the maximum displacement of the structure and the maximum inter-story drift increase that indicates a decrease in lateral stiffness of the structure. This is consistent with the results obtained in previous sections. Moreover, the comparison of maximum inter-story drift in single-layer and double-layer diagrid structures shows that the drift value can be controlled by proper combination of internal and external angles in double-layer diagrid structure. Fig. 13 shows the average amount of energy dissipated by the structures under the applied earthquake records. According to this figure, a

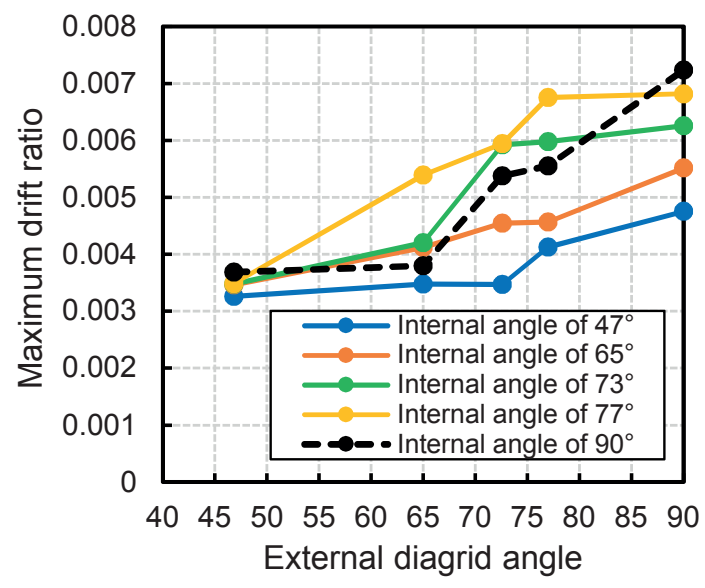

Fig. 11 Mean maximum inter-story drift of studied structures obtained by nonlinear dynamic analyses

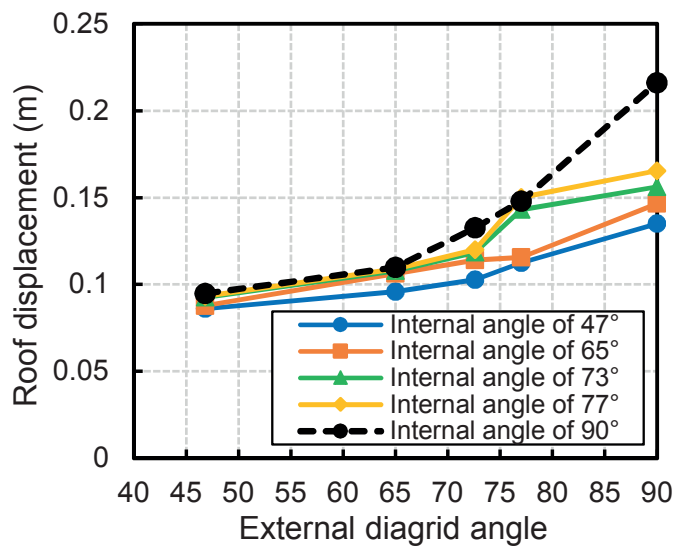

Fig. 12 Mean maximum roof displacement of studied structures obtained by nonlinear dynamic analyses

double-layer diagrid system with the same angles for internal and external diagonal members has a good performance in energy dissipation. The results of nonlinear dynamic analysis show the proper performance of double-layer diagrid structures in comparison with conventional (single-layer) diagrid structures. Nevertheless, achieving the optimal combination of angles for internal and external diagonal members requires more comprehensive studies. 


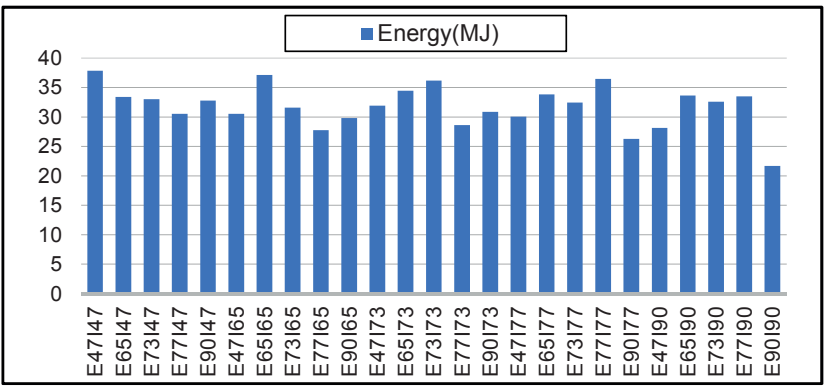

Fig. 13 The average amount of dissipated energy obtained by nonlinear dynamic analyses

\section{Evaluation of seismic performance of double-layer diagrid structures and choosing the best model}

The results obtained from nonlinear static and dynamic analyses are used to evaluate the seismic performance of the diagrid structures. The most important parameters used in this assessment are: strength $(R)$, stiffness $(K)$, ductility $(\mu)$, dissipated energy $(E)$, drift safety margin $(D S M)$, and the total weight of the interior and exterior frames $(W)$.

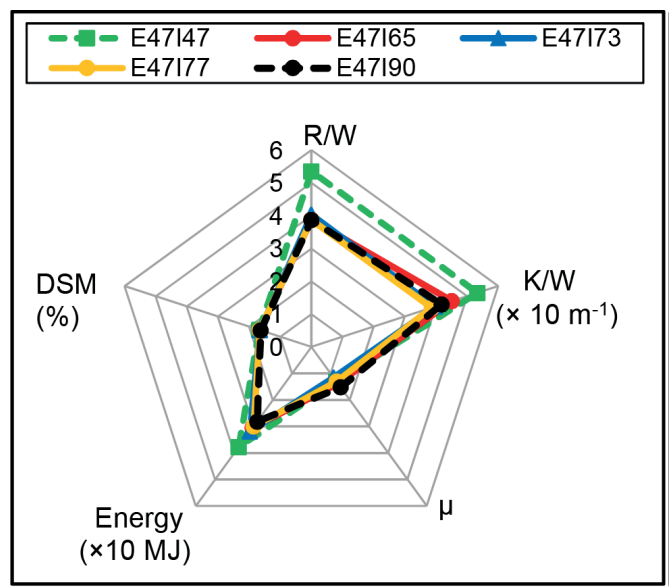

(a) The angle of $47^{\circ}$ for external diagonals

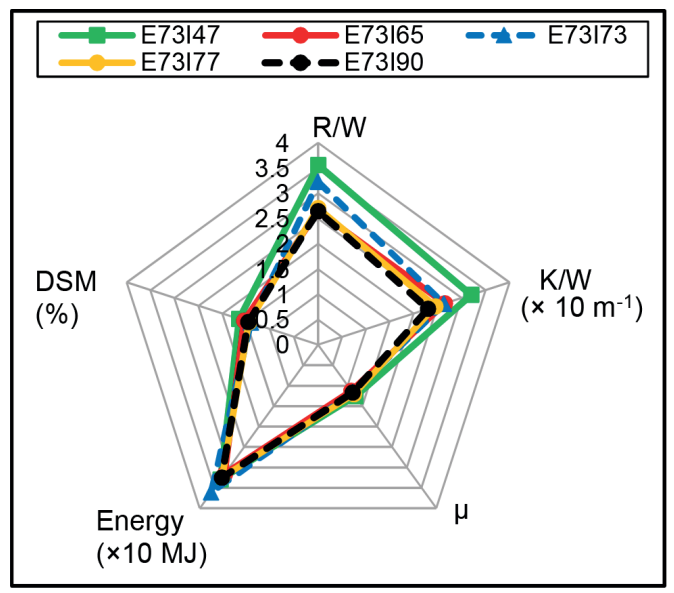

(c) The angle of $73^{\circ}$ for external diagonals
The values of $R, K$, and $\mu$ are calculated from nonlinear static analysis; and nonlinear dynamic analysis is used to calculate the $E$ and $D S M$ values. It should be noted that the drift safety margin is defined as DSM $=0.02$-(maximum inter-story drift ratio), in which 0.02 is the allowable story drift ratio based on ASCE7-10. The values of $R / W$ (structural efficiency), $K / W$ (specific strength), $\mu, E$ and $D S M$ for the diagrid structures are presented in Fig. 14. In these figures, the conventional diagrid model (single-layer diagrid) is shown in black dot and the best-performance structure is shown using the color dot. As shown by results, the twolayer diagrid structures are more suitable than the conventional diagrid systems for satisfying the stiffness and strength criteria, dissipating the input energy of the earthquake and providing the safety margin against collapse. It is also possible to improve the ductility of the proposed system by appropriately combining the angles of internal and external diagonal members. Taking into account the all indices under consideration simultaneously, it can be

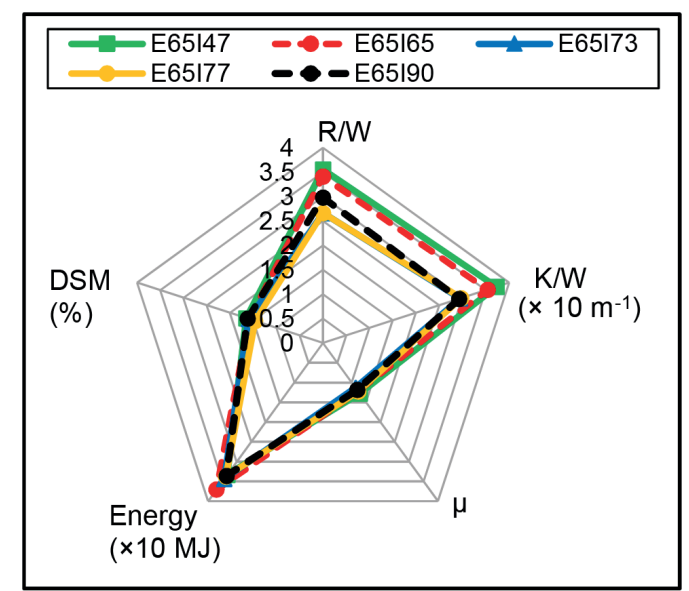

(b) The angle of $65^{\circ}$ for external diagonals

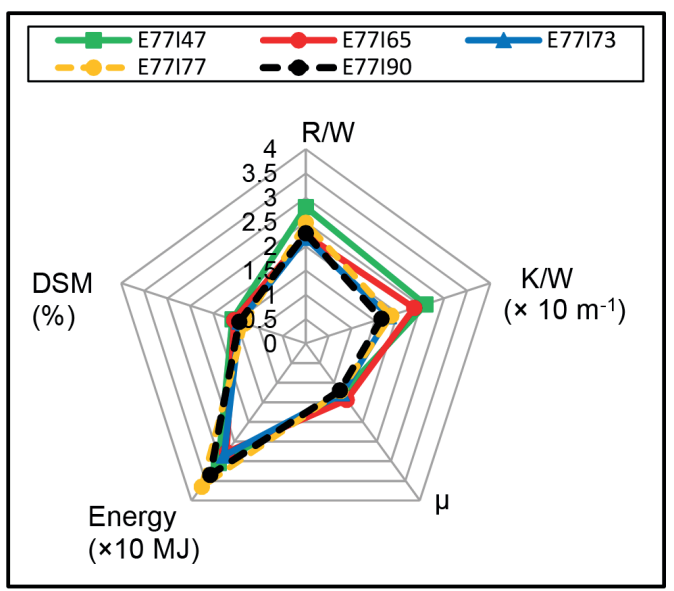

(d) The angle of $77^{\circ}$ for external diagonals

Fig. 14 The comparison of the performance indices for the studied diagrid models 
stated that in the present study, diagrid structures with the same internal and external angles of diagonals have better performances. For example, the use of a two-layer diagrid system with identical angles of $65^{\circ}$ for internal and external diagonal members has caused the strength, stiffness, ductility and dissipated energy amount to rise by $14 \%$, $21 \%, 7 \%$, and $10 \%$ respectively in comparison with a single-layer diagrid system with inclination of diagonal members of $65^{\circ}$. Fig. 15 shows performance indices for structures with exterior moment-resisting and interior diagrid frames. In these structures, by increasing the angle in the interior diagrid, the strength, stiffness and dissipated energy by the structures decrease.

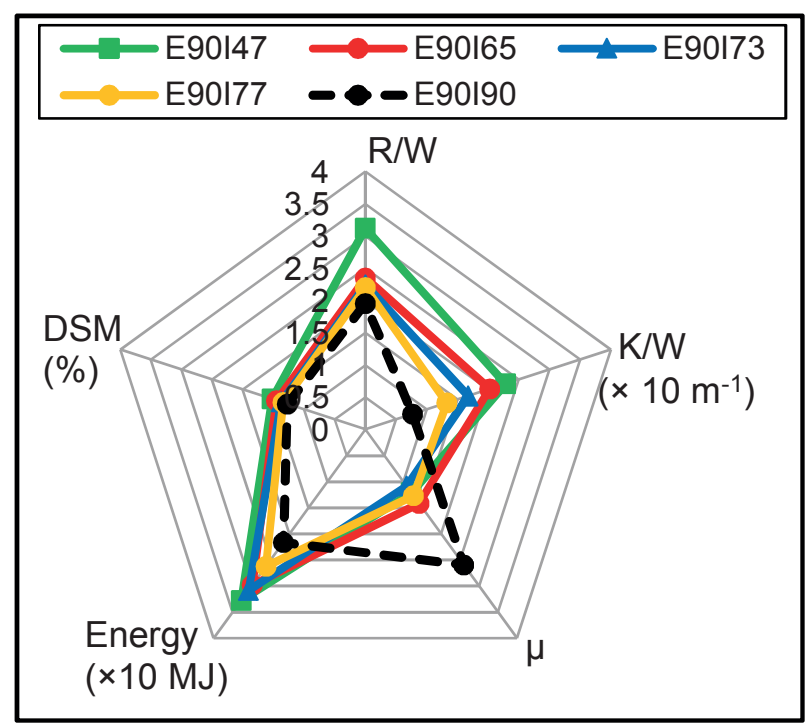

Fig. 15 Performance indices for structures with exterior momentresisting and interior diagrid frames

\section{References}

[1] Kim, J., Lee, Y.-H. "Seismic performance evaluation of diagrid system buildings", The Structural Design of Tall and Special Buildings, 21(10), pp. 736-749, 2012.

https://doi.org/10.1002/tal.643

[2] Moon, K.-S., Connor, J. J., Fernandez, J. E. "Diagrid structural systems for tall buildings: characteristics and methodology for preliminary design", The Structural Design of Tall and Special Buildings, 16(2), pp. 205-230, 2007.

https://oi.org/10.1002/tal.311

[3] Moon, K. S. "Optimal Grid Geometry of Diagrid Structures for Tall Buildings", Architectural Science Review, 51(3), pp. 239-251, 2008.

https://doi.org/10.3763/asre.2008.5129

[4] Zhang, C., Zhao, F., Liu, Y. "Diagrid tube structures composed of straight diagonals with gradually varying angles", The Structural Design of Tall and Special Buildings, 21(4), pp. 283-295, 2012. https://doi.org/10.1002/tal.596

\section{Conclusions}

A double-layer diagrid system was proposed in the present study. At first, the equations for the lateral stiffness of the system were obtained, and then, by modeling a number of diagrid systems, their seismic performance was examined and compared with the conventional diagrid system, in which the diagonal grids are located around the structure, and the inner frames with vertical columns only bear gravity loads. One of the benefits of this system - especially in high-rise buildings - is to provide the required stiffness through distribution of stiffness in interior and exterior diagrid frames. To achieve this, there are several alternatives to the designer: (1) to concentrate stiffness in the interior diagrid frame by increasing the cross-section area of its members and reducing the cross-section area of the members in the exterior diagrid (2) to concentrate stiffness in the exterior diagrid frame by increasing the cross-section area of its members and reducing the cross-section area of the members in the interior diagrid (3) different combinations of diagonal angles in interior and exterior frames to achieve the desired stiffness (4) combination of the alternative 3 with 1 or 2 . Each of these solutions will be usable according to the intended architectural function.

Two-layer diagrid structures have better performance in satisfying the stiffness and strength criteria than conventional diagrid systems. Although the main focus of the research has been on stiffness criterion, the preliminary results show that with an appropriate combination of internal and external angle, in addition to the improvements in ductility, the amount of energy dissipation by the structures could also be increased which requires more extensive research.

[5] Zhao, F., Zhang, C. "Diagonal arrangements of diagrid tube structures for preliminary design", The Structural Design of Tall and Special Buildings, 24(3), pp. 159-175, 2015.

https://oi.org/10.1002/tal.1159

[6] Montuori, G. M., Mele, E., Brandonisio, G., De Luca, A. "Design criteria for diagrid tall buildings: Stiffness versus strength", The Structural Design of Tall and Special Buildings, 23(17), pp. 1294 $1314,2014$.

https://doi.org/10.1002/tal.1144

[7] Milana, G., Olmati, P., Gkoumas, K., Bontempi, F. "Ultimate Capacity of Diagrid Systems for Tall Buildings in Nominal Configuration and Damaged State", Periodica Polytechnica Civil Engineering, 59(3), pp. 381-391, 2015. https://doi.org/10.3311/PPci.7795

[8] Computer and Structures Inc. "User Guide PERFORM-3DTM Nonlinear Analysis and Performance Assessment for 3D Structures", [pdf] Computer and Structures, Inc., Berkeley, CA, USA, 2013. Available at: http://docs.csiamerica.com/manuals/perform-3d/Perform3D\%20 User\%20Guide.pdf\#page=1 [Accessed: 12 November 2019] 
[9] ASCE "ASCE 7-10 Minimum Design Loads for Buildings and Other Structures", American Society of Civil Engineers, Reston, VA, USA, 2010.

https://doi.org/10.1061/9780784412916

[10] AISC "AISC 360-10 Specification for Structural Steel Buildings", [pdf] American Institute of Steel Construction, Chicago, IL, USA, 2010. Available at: https://www.aisc.org/globalassets/productfiles-not-searched/historic-standards/specification-for-structural-steel-buildings-360-10.pdf [Accessed: 12 November 2019]
[11] Computers and Structures Inc. "ETABS Integrated building design software (v18)", [computer program] Computers and Structures, Inc., Berkeley, CA, USA, 2013. Available at: https://www.csiamerica.com/products/etabs [Accessed: 12 November 2019]

[12] ASCE "ASCE 41-13 Seismic Evaluation and Retrofit of Existing Buildings", American Society of Civil Engineers, Reston, VA, USA, 2014.

https://doi.org/10.1061/9780784412855 